\title{
Career intention at the end of core medical training
}

\author{
Authors: Matthew Roycroft, ${ }^{A}$ Sarah Kaufmann ${ }^{B}$ and Peter Hammond ${ }^{B}$
}

\section{Introduction}

In $2018,38 \%$ of foundation trainees proceeded directly into specialty training, down from $71 \%$ in $2011 .{ }^{1}$ It's estimated that $50 \%$ of core medical trainees (CMTs) go directly onto higher training. Common reasons for career breaks include travelling, parental leave, non-training clinical work and 'health and wellbeing'?

Here we present an exit survey of CMTs in Yorkshire and the Humber (Y\&H), exploring career intentions and reasons behind choices.

\section{Methods}

All CMTs in Y\&H expecting to complete core medical training in summer 2018 were invited to complete an online survey in June/July 2018. Participation was voluntary, with no identifying information collected.

Question style was selected for appropriateness to each individual question, with multiple styles used. Free-text responses were categorised during analysis, with no pre-defined categories. Subgroup analysis looked at influence of demographic factors on decisions.

\section{Results}

Fifty-seven trainees ( $45 \%$ of those eligible) responded, with 42 $(74 \%)$ expecting to complete core medical training that summer. Of those completing core medical training, 28 (67\%) were proceeding directly into higher training; 13 (31\%) were taking time out and then planned to continue in higher training; and one planned to take time out, reassess plans later but not necessarily continue into higher specialty training. None planned to leave physicianly or UK training in the long term.

Twelve respondents taking time out were questioned regarding their plans, and could select more than one response. Nine (75\%) were gaining further experience prior to being a medical registrar, nine were working patterns that were not possible in training, seven were gaining experience to help decide on specialty, and four were developing their $\mathrm{CV}$ for competitive applications.

Seventeen $(61 \%)$ of those aged under 30 planned to continuing training directly, compared with 11 (79\%) of those aged over 30 .

\footnotetext{
Authors: ${ }^{\mathrm{A}}$ The Rotherham NHS Foundation Trust. Rotherham, UK; ${ }^{B}$ Health Education England, working across Yorkshire and the Humber, UK
}

Sixteen (64\%) women were continuing directly, compared with $12(71 \%)$ men. Nineteen $(61 \%)$ who had obtained their primary qualification in the UK planned to continue immediately, compared with eight $(80 \%)$ who obtained it outside the European Economic Area.

\section{Discussion and conclusion}

This survey has two significant results: upon completion of core medical training, almost all trainees want to pursue physicianly careers in the long term, and the decision to take time out of training is multifactorial, with 12 trainees selecting 31 reasons. Three reasons were common: working a pattern that was impossible in training; gaining experience prior to being a medical registrar; and to aid competitive selection.

Two of the common reasons are addressed by the internal medicine curriculum, ${ }^{3}$ which should widen experience and prepare trainees better for senior roles. Increased flexibility was highlighted in the 2016 contract negotiations ${ }^{4}$ and much is being done to address this, with the Royal College of Physicians and Health Education England (HEE) introducing 'flexible portfolio training,' HEE piloting opening up less-than-full-time training and exploring 'step-on, step-off' training. ${ }^{5,6}$ This survey should be repeated after these changes.

\section{References}

1 UK Foundation Programme Office. F2 career destinations report 2018. Birmingham: UKFPO, 2018. www.foundationprogramme.nhs. uk/sites/default/files/2019-01/F2\% 20Career \% 20Destinations \% 20 Report_FINAL.pdf [Accessed 3 April 2019].

2 British Medical Association. Understanding trends among current doctors in training. London: BMA, 2018. www.bma.org.uk/collectivevoice/policy-and-research/education-training-and-workforce/juniorscareer-survey [Accessed 3 April 2019].

3 Joint Royal Colleges of Physicians Training Board. Internal medicine stage 1 curriculum. London: JRCPTB, 2018. www.jrcptb.org.uk/newinternal-medicine-curriculum [Accessed 3 April 2019].

4 Health Education England. Enhancing working lives. Leeds: HEE, 2018. www.hee.nhs.uk/our-work/doctors-training/enhancingworking-lives [Accessed 3 April 2019].

5 Health Education England. Enhancing junior doctors' working lives - a progress report 2018. Leeds: HEE, 2018. www.hee.nhs.uk/our-work/ doctors-training/enhancing-working-lives [Accessed 3 April 2019].

6 Health Education England. Delivering greater flexibility. Leeds: HEE, 2018. www.hee.nhs.uk/our-work/doctors-training/delivering-greaterflexibility [Accessed 3 April 2019]. 